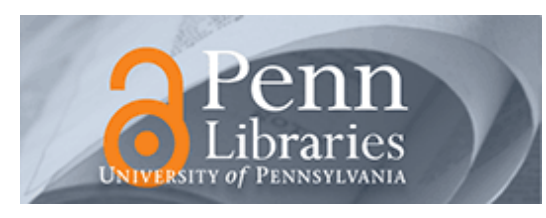

University of Pennsylvania ScholarlyCommons

Finance Papers

Wharton Faculty Research

$7-1986$

\title{
Comment on Kotlikoff, Shoven, and Spivak
}

Andrew B. Abel

University of Pennsylvania

Follow this and additional works at: http://repository.upenn.edu/fnce_papers

Part of the Finance and Financial Management Commons

\section{Recommended Citation}

Abel, A. B. (1986). Comment on Kotlikoff, Shoven, and Spivak. Journal of Labor Economics, 4 (3(2)), S208-S215. http://dx.doi.org/ $10.1086 / 298128$

At the time of publication, author Andrew B. Abel was affiliated with the Harvard University \& National Bureau of Economic Research . Currently (September 2017), he is a faculty member in the Finance Department of the Wharton School at the University of Pennsylvania.

This paper is posted at ScholarlyCommons. http://repository.upenn.edu/fnce_papers/4

For more information, please contact repository@pobox.upenn.edu. 


\title{
Comment on Kotlikoff, Shoven, and Spivak
}

\begin{abstract}
In the absence of perfect annuity markets, individual consumers generally undertake precautionary saving to provide resources for their future consumption in the event that they live longer than expected. Kotlikoff, Shoven, and Spivak (in this issue) (hereafter KSS) have provided us with a well-conceived and well-executed study of the effects of various annuity arrangements on individual and aggregate saving in the presence of lifetime uncertainty. Each of these authors has had a long-standing interest in this area, and their current paper reflects their accumulated expertise. Their results indicate that a potentially sizable fraction of U.S. household wealth represents precautionary saving resulting from the absence of perfect annuity market.
\end{abstract}

\section{Disciplines}

Finance and Financial Management

\section{Comments}

At the time of publication, author Andrew B. Abel was affiliated with the Harvard University \& National Bureau of Economic Research . Currently (September 2017), he is a faculty member in the Finance Department of the Wharton School at the University of Pennsylvania. 


\title{
Comment on Kotlikoff, Shoven, and Spivak
}

\author{
Andrew B. Abel, Harvard University and \\ National Burean of Economic Research
}

In the absence of perfect annuity markets, individual consumers generally undertake precautionary saving to provide resources for their future consumption in the event that they live longer than expected. Kotlikoff, Shoven, and Spivak (in this issue) (hereafter KSS) have provided us with a well-conceived and well-executed study of the effects of various annuity arrangements on individual and aggregate saving in the presence of lifetime uncertainty. Each of these authors has had a long-standing interest in this area, and their current paper reflects their accumulated expertise. Their results indicate that a potentially sizable fraction of U.S. household wealth represents precautionary saving resulting from the absence of perfect annuity markets.

The strategy of the KSS paper is to develop simple models of individual saving behavior on the basis of utility maximization and then to aggregate the behavior of individuals both intra- and intertemporally. By comparing the results of models that differ in the specification of bequest motives and opportunities for creating annuities, KSS provide insights about the effects of various annuity arrangements on saving and capital accumulation. Although the models are all conceptually simple, analytic solutions cannot be obtained in many cases. Therefore, KSS provide numerical solutions to their models. In addition, because the models are conceptually

[Journal of Labor Economics, 1986, vol. 4, no. 3, pt. 2]

(C) 1986 by The University of Chicago. All rights reserved.

0734-306X/86/0403-0014\$01.50 
simple, KSS are able to provide intuitive explanations for most of their findings.

\section{Bequest Motives}

The literature on uncertain lifetimes and bequests contains at least five different types of motives for leaving bequests. (a) There may be no motive for leaving bequests, but bequests may occur accidentally when a consumer, holding some precautionary saving, dies. Abel (1985) and Eckstein, Eichenbaum, and Peled (in press) have examined accidental bequests in overlapping generations economies. (b) Consumers may obtain utility directly from leaving a legacy at death. This utility can be simply written as a function of the size of the legacy at death, as in Yaari's (1965) seminal paper. (c) Consumers may have a "paternalistic" bequest motive in which they care not only about their own consumption but also about the consumption of their children. Goldman (1979), however, has shown that this formulation of the utility function leads to problems of dynamic inconsistency in the sense of Strotz (1956). (d) Consumers may obtain utility from their own consumption and from the utility of their heirs. Barro (1974) has termed this formulation an "altruistic" bequest motive. (e) Bequests may occur as the result of gametheoretic interactions among selfish consumers as in Kotlikoff, Shoven, and Spivak (1983) and Bernheim, Shleifer, and Summers (in this issue).

In their paper, KSS have chosen to focus on models in which bequests arise because of either motive $d$ or motive $e$. The exclusion of motives $a, b$, and $c$ seems quite appropriate. The effects on individual saving and aggregate capital accumulation of introducing a perfect annuity market when bequests are entirely accidental (motive $a$ ) has already been studied elsewhere (Abel 1985). It is worth noting that, in contrast to the simulation results presented for the models in KSS, the introduction of a perfect annuity market into a model with only accidental bequests can lead to an increase in steady-state aggregate capital stock if the coefficient of relative risk aversion is below a certain critical value (which is less than one). Although motive $b$ provides an analytically convenient formulation, this specification is often justified by claiming that it is a convenient way of capturing the fact that a consumer cares about the utility of his children, that is, motive $d$. (See, e.g., Sheshinski and Weiss 1981.) Thus KSS seem quite justified in examining motive $d$ and ignoring motive $b$. Finally, the exclusion of motive $c$ seems warranted in the light of the dynamic consistency problems associated with it.

\section{An Alternative Interpretation of the Parameters of the Utility Function}

The KSS specification of the "intergenerationally altruistic" utility function differs from the conventional formulation based on Barro (1974). 
In order to make this point clearly and to highlight the differences in interpretation of the preference parameters, I consider the special case in which all consumers live for 4 periods with certainty (i.e., $P=1$ in the KSS notation). Let $W_{t}$ denote the family's total wealth at the beginning of period $t$, and let $c_{t, i}$ be the consumption in the $i$ th period of life of a consumer born at the beginning of period $t$. Then the utility function in equation (2) of KSS can be written as

$$
V\left(W_{t}\right)=\max \left[u\left(c_{t-2,3}\right)+\theta u\left(c_{t, 1}\right)+\alpha u\left(c_{t-2,4}\right)+\theta \alpha u\left(c_{t, 2}\right)+\alpha^{2} V\left(W_{t+2}\right)\right],
$$

where, in the KSS formulation, $u(\quad)$ is a constant relative risk aversion utility function. Solving equation (1) recursively yields

$$
V\left(W_{t}\right)=\max \left[u\left(c_{t-2,3}\right)+\alpha u\left(c_{t-2,4}\right)+\sum_{i=0}^{\infty} \alpha^{2 i} U\left(C_{t+2 i}\right)\right],
$$

where

$$
\begin{aligned}
U\left(C_{s}\right) & =\theta u\left(c_{s, 1}\right)+\theta \alpha u\left(c_{s, 2}\right)+\alpha^{2} u\left(c_{s, 3}\right)+\alpha^{3} u\left(c_{s, 4}\right) \\
s & =t, t+2, t+4, \ldots
\end{aligned}
$$

Before interpreting the utility function in equation (2), recall that, in the Barro formulation of the utility function, a consumer obtains utility from the utility of his heir(s) as well as directly from his own consumption. A convenient specification of this utility function is

$$
V_{t}^{*}\left(W_{t}\right)=\max \left[U^{*}\left(C_{t}\right)+\pi^{d} V_{t+d}^{*}\left(W_{t+d}\right)\right],
$$

where $C_{t}$ is the vector of lifetime consumption by the consumer born at the beginning of period $t, U^{*}\left(C_{t}\right)$ is the utility that the consumer obtains directly from his own consumption, $W_{t}$ is the wealth held at birth by a consumer born at the beginning of period $t$, and $d$ is the number of periods between the birth of successive generations. The parameter $\pi$ can be interpreted as $\pi=(1+\mu)^{-1}$, where $\mu$ is the rate of preference (per period) of a consumer for the utility of his own consumption over the utility of his heir. Time preference per se is embodied in the function $U^{*}\left(C_{t}\right)$. Solving (3) recursively yields

$$
V_{t}^{*}\left(W_{t}\right)=\max \sum_{i=0}^{\infty} \pi^{d i} U^{*}\left(C_{t+d i}\right)
$$

Now consider the case in which consumers live for 4 periods and in which $d=2$. As of time $t$, the consumer born at time $t-2$ maximizes 


$$
U^{*}\left(\underline{c}_{t-2,1}, \underline{c}_{t-2,2}, c_{t-2,3}, c_{t-2,4}\right)+\pi^{2} \sum_{i=0}^{\infty} \pi^{2 i} U^{*}\left(C_{t+2 i}\right)
$$

where the bar under $c_{t-2,1}$ and $c_{t-2,2}$ indicates that these two consumption levels already have been chosen.

We can now interpret the parameters in the KSS utility function (my eq. [1]) by recalling that (1) is equivalent to (2) and then observing that the right-hand side of (2) is a special case of (5). In equation (5), $\pi$ is the discount factor (per period) that a consumer applies to the utility of his heir. A comparison of (2) and (5) reveals that $\alpha$ plays the same role as $\pi$ and thus measures the discounting due to the preference for one's own consumption over the utility of one's child. This interpretation differs from the KSS interpretation of $\alpha$ as the "time preference factor."

The rate of time preference relating the utility of one's own consumption at different dates is not constant in the KSS formulation. The discount factor reflecting time preference for first-period consumption relative to second-period consumption is $\alpha$, for second-period consumption relative to third-period consumption is $\alpha / \theta$, and for third-period consumption relative to fourth-period consumption is $\alpha$. If we impose the restriction that the rate of time preference is always nonnegative or, equivalently, that the discount factor never exceeds one, then $\alpha$ must be less than or equal to $\theta$.

Interpreting $\alpha$ as a measure of the bequest motive rather than as a measure of time preference does not, of course, invalidate the KSS numerical simulation results, although it does indicate that a different set of parameters may be considered the "most relevant." More important, the KSS assertion that (with perfect insurance), in the steady state, $R$, defined as $\left[1+f^{\prime}(k)\right]^{-1}$, where $f^{\prime}(k)$ is the marginal product of capital, is equal to $\alpha$ continues to hold true under the interpretation proposed above that $\alpha$ reflects the preference for one's own consumption over one's heir's utility. Indeed, Samuelson (1968) derived his well-known Two-Part Golden Rule using the utility function (4) (with $d=1$ ) and found that, with a constant population, the steady state is characterized by the equality of the marginal product of capital and the rate of preference for one generation over the succeeding generation; the "longrun equilibrium is quite independent of the subjective time preference of the representative individual during his own lifetime" (p. 89). More recently, Burbridge (1983) has used a recursive specification similar to (3) and also obtained the result that the marginal product of capital is equal to the discount rate applied to the utility of the succeeding generation. Although Samuelson and Burbridge ignored the uncertainty of the date of death, this result continues to hold with lifetime uncertainty if there are perfect insurance and annuity markets. 


\section{The Distribution of Wealth}

The stochastic nature of the date of death leads to a nondegenerate distribution of wealth even if all consumers are identical ex ante. Although all consumers have the same ex ante mortality probabilities, some consumers in each generation die young and some consumers die old. In the absence of perfect annuity markets, consumers who die at different ages will in general leave bequests of different sizes. Therefore, the inheritances received by members of subsequent generations will depend on the mortality history of their families, and there will be a nondegenerate cross-sectional distribution of wealth. In Section II, KSS present an intriguing result for the distribution of wealth in an economy populated by consumers with intergenerational altruism. They show that, if consumers are allowed to borrow against their own future income and the future income of their heirs, then the distribution of income in the absence of an annuity market tends toward complete inequality. More precisely, they show that, with probability one, the wealth of a given family will be zero in the long run; all the economy's wealth is held by families in a set of measure zero. On reading this result, two questions occur to the reader. First, why? Second, how might the model be reasonably altered to get rid of this result? To both of these questions KSS provide excellent answers. I offer an alternative interpretation below.

The result that with probability one a family will have zero wealth in the long run bears a striking similarity to the gambler's-ruin problem in which, with probability one, a gambler facing a series of fair bets will go broke. In the KSS model one can view the family as facing a series of bets on whether the 3-period-old consumer will end up living 3 or 4 periods. If the consumer dies after the third period, the family wins an amount $(D-1) W_{t}>0$, but if the consumer lives after the third period, the family "wins" an amount $(A-1) W_{t}<0$. The expected payoff from this bet is $[(1-P)(D-1)+P(A-1)] W_{t}$, which, according to equation (7) in KSS, is equal to zero. Thus each bet faced by the family is fair. One can interpret the KSS result as a demonstration that a gambler who always wagers a constant share of his wealth at a given set of fair odds will go broke with probability one.

By altering the model of Section II to prohibit consumers from borrowing against future income, KSS are able to eliminate the complete inequality result. Using the terminology of the gambler's-ruin problem, it is clear that prohibiting the gambler from mortgaging his future income prevents him from ever going broke. (The gambler's-ruin logic of the previous paragraph also breaks down in this case because it is no longer true that every bet of every family has zero expected value. In the steady state it is true that the expected [= actual] value of aggregate wealth 2 periods hence is always equal to current aggregate wealth. 
However, for some families expected wealth 2 periods hence exceeds their current wealth, and for some families expected wealth 2 periods hence is less than their current wealth.)

\section{Implications for Policy}

Although the focus of the KSS paper is not on government policy, the issues discussed are of concern to policymakers, and KSS offer some remarks on policy. They point out that their results imply that the insurance aspects of social security may reduce the long-run capital stock by even more than the "pay-as-you-go" aspect. While this observation may indeed be correct, one must note the following important difference between the provision of annuities through the social security system and the provision of annuities through the market: because the actuarially fair rate of return exceeds the rate of return on riskless bonds (if $R_{B}$ is the gross rate of return on riskless bonds, and if $P$ is the probability of survival, then the actuarially fair gross rate of return on annuities is $R_{B} / P$ ), the introduction of a private annuity market raises the rate of return on private savings, and the increase in the rate of return has both income and substitution effects. However, even if social security could offer the same rate of return as the private annuity market (and indeed a fully funded system could offer the actuarially fair rate of return without running a deficit or a surplus), the introduction of social security would differ from the introduction of a private annuity market because there is no substitution effect associated with the introduction of social security. If the rate of return on social security is greater than the rate on riskless bonds, then the introduction of social security would have a positive income effect. However, because consumers cannot individually choose how much saving to hold in the form of social security, there is no substitution effect associated with the higher rate of return on saving offered by social security. Put differently, the introduction of social security does not change a consumer's intertemporal terms of trade. Thus one must be cautious in applying results about the effects of private annuities to questions concerning the introduction of social security. Sheshinski and Weiss (1981) have proposed an optimal social security system in the presence of lifetime uncertainty in which the government establishes a social security system to provide the amount of annuities that private consumers would choose if there were a competitive annuity market. However, the design of an optimal social security system is easier in the Sheshinski-Weiss model because they assume that all consumers in a given cohort die at the same time, thereby eliminating intracohort variation in bequests and wealth. In the KSS model, there is intracohort variation in wealth so that different consumers in a given cohort would demand different amounts of social security. This feature of the model (and of the world) complicates the design of an optimal 
social security system because consumers who are alive when the social security system is introduced would not agree on the appropriate amount of social security coverage.

Because the introduction of a perfect annuity market generally reduces the steady-state capital stock, it also reduces steady-state aggregate consumption (provided that the marginal product of capital exceeds the population growth rate). It is possible, KSS point out, that in the steady state the consumption of every consumer may be lower in the presence of an annuity market than in its absence. This apparently paradoxical result serves to remind us that, in evaluating the effects of policy, we may not want to focus simply on the steady state but may want also to consider the welfare of consumers on the transition path to the new steady state. In the selfish life-cycle model, the policymaker would have to prescribe a social welfare function that weights the utility of consumers in different generations. Using the social welfare function analyzed by Samuelson (1968) leads to the modified Golden Rule in which steadystate aggregate consumption is lower than its maximum feasible value.

Finally, if we are to examine the desirability of the government's provision of annuities, then it would be useful to include in the model the reason(s) that annuities are not provided by the market. For instance, if consumers have different ex ante mortality probabilities, then adverse selection could be sufficiently severe to preclude the operation of a private market for annuities. A compulsory system of annuities (such as social security) would be immune to adverse selection. To evaluate the desirability of social security, the model would have to include the heterogeneity and adverse selection that gave rise to the possible desirability of social security in the first place, as in Abel (1984).

At the close of their paper, KSS provide a brief agenda for future research on the aggregate implications of individual lifetime uncertainty and precautionary saving. In addition to analyzing the effects of uncertainty with respect to future health status and future earnings, it would be of interest to analyze the effects of uncertainty of future government policy. For instance, social security may have very different effects, depending on consumers' assessments of the likelihood that the social security system will be able to deliver its promised benefits when current young consumers are old. More generally, future research might usefully examine the effects of aggregate uncertainty as well as individual uncertainty. We already have learned a great deal about precautionary saving, capital accumulation, and the distribution of wealth from Kotlikoff, Shoven, and Spivak. Their future research should continue to deepen our understanding of these topics.

\section{References}

Abel, Andrew B. "Capital Accumulation and Uncertain Lifetimes with Adverse Selection." Mimeographed. Cambridge, Mass.: Harvard University, Department of Economics, 1984. 
"Precautionary Saving and Accidental Bequests." American Economic Review 75 (September 1985): 777-91.

Barro, Robert J. "Are Government Bonds Net Worth?" Journal of Political Economy 82 (November/December 1974): 1095-1117.

Bernheim, B. Douglas; Shleifer, Andrei; and Summers, Lawrence H. "The Strategic Bequest Motive." In this issue.

Burbridge, John. "Government Debt in an Overlapping-Generations Model with Bequests and Gifts." American Economic Review 73 (March 1983): 222-27.

Eckstein, Zvi; Eichenbaum, Martin; and Peled, Dan. "The Distribution of Wealth and Welfare in the Presence of Incomplete Annuity Markets." Quarterly Journal of Economics (in press).

Goldman, Steven Marc. "Intertemporally Inconsistent Preferences and the Rate of Consumption." Econometrica 47 (May 1979): 621-26.

Kotlikoff, Laurence; Shoven, John B.; and Spivak, Avia. "Annuity Markets, Savings and the Capital Stock." NBER Working Paper no. 1250. December 1983.

- "The Effect of Annuity Insurance on Savings and Inequality." In this issue.

Samuelson, Paul A. "The Two-Part Golden Rule Deduced as the Asymptotic Turnpike of Catenary Motions." Western Economic Journal 6 (March 1968): 85-89.

Sheshinski, Eytan, and Weiss, Yoram. "Uncertainty and Optimal Social Security Systems." Quarterly Journal of Economics 95 (May 1981): 189206.

Strotz, Robert H. "Myopia and Inconsistency in Dynamic Utility Maximization." Review of Economic Studies 23 (1956): 165-80.

Yaari, Menachem E. "Uncertain Lifetime, Life Insurance and the Theory of the Consumer." Review of Economic Studies 32 (1965): 137-50. 